\title{
Role of MDCT in Assessment of Mediastinal Masses
}

Dr. Manish Bhagat ${ }^{1}$, Dr. Vaishali Kundu ${ }^{2 *}$, Dr. Eliza Kapadia ${ }^{3}$

${ }^{1}$ Associate Professor, Sri Aurobindo Institute of Medical Sciences and Post Graduate Institute, India

${ }^{2,3}$ Resident, Sri Aurobindo Institute of Medical Sciences and Post Graduate Institute, India

DOI: $10.36347 /$ sjams.2021.v09i02.006

| Received: 22.01.2021 | Accepted: 08.02.2021 | Published: 11.02.2021

*Corresponding author: Vaishali kundu

Abstract

Original Research Article

Aim: Role of Multidetector Computed Tomography in Evaluation of Mediastinal Masses. Objectives: 1.To differentiates between benign and malignant mass lesions based on MDCT characteristics. 2. To evaluate the ability of MDCT to differentiate mediastinal masses based on CT characteristics and location. Result: Patient between 41 to 60 years is the most common age group having mediastinal mass and anterior mediastinal mass is the most common mediastinal mass. Conclusion: Multidetector computed tomography is a very useful modality in evaluating the mediastinal lesions, and provides precise information regarding the extent, tissue composition, lesion pattern enhancement and mediastinal and vascular invasion.

Keywords: Carcinoma, MDCT - Multi Detector Computed Tomography, HU - Hounsfield Unit.

Copyright $(\odot) 2021$ The Author(s): This is an open-access article distributed under the terms of the Creative Commons Attribution 4.0 International License (CC BY-NC 4.0) which permits unrestricted use, distribution, and reproduction in any medium for non-commercial use provided the original author and source are credited.

\section{INTRODUCTION}

Mediastinal lesions include a wide range of pathologies, varying from neoplasms (benign \& malignant), cysts, vascular anomalies, and lymph nodes. [1Computed tomography (CT) has evolved as one of the most important tool in the assessment of a mediastinal mass. Description on CT is based on different attenuation of air, fat, water and calcium [4]. High-resolution multiplanar reformation images display the detailed relationship of the lesion with neighboring structures. MDCT was introduced into clinical radiology in 1998 and this constituted an evolutionary step in the development and refinement of CT techniques. MDCT allows significant anatomical volumes to be covered with isotropic sub-millimeter spatial resolution.[5]High resolution MDCT scans have the ability to accurately localize lesions along with the demarcation of neighboring structures has made it the diagnostic modality of choice for mediastinum and its pathologies. MDCT with MPR and VR reconstructions also provides data regarding airway invasion and patency, extent of tumor, presence or absence of collateral vessels and enhancement pattern. Mediastinal invasion from nearby malignancies like lung carcinomas and mesotheliomas, can be better assessed on MDCT with the help of reconstructed images where loss of fat planes is seen between the lesion and the adjacent organ.[3].In this study by following a systemic approach to complex mediastinal anatomy incorporating the patients clinical history, radiographic findings, MDCT characteristics, location, enhancement patterns a short meaningful differential diagnosis and often a definitive diagnosis could be predicted[5].

\section{Materials AND Method}

Prospective observational study was carried out from December 2018 to June 2020 in the department of Radiodiagnosis, SAMC \& PG Institute, Indore. Patient's fulfilling our inclusion and exclusion criteria referred for MDCT chest with clinical suspicion of mediastinal lesions lesions on basis of their location, extent, probable tissue of origin, CT characteristics and enhancement pattern from various departments of our institution constituted the study population and were subjected to MDCT chest, after taking written informed consent from the patient, the final study population of our study was 50 .

\section{Inclusion criteria}

1. Patients of both sexes of any age group clinically suspected to have mediastinal mass lesion.

2. Suggestion of mediastinal widening/mass on chest radiograph.

\section{Exclusion criteria}

The following patients will be excluded from the study -

1. History of hypersensitivity to intravenous contrast agents;

2. Deranged renal functions.

3. Post-surgical patients;

4. Pregnant women;

5. Post traumatic patients; 
Manish Bhagat et al; Sch J App Med Sci, Feb, 2021; 9(2): 202-205

6. Lesion of vascular origin/cardiac masses.

7. Patients who are not giving consent.

\section{Data collection procedure}

Each patient underwent a thorough clinical evaluation including a detailed history and physical examination. The duration of the complaints were noted in each patient.

All the patients were made to undergo MDCT scan as the radiological examination after taking an informed consent for the samel

Table-1: Age and sex distribution

\begin{tabular}{|l|l|l|l|}
\hline \multirow{2}{*}{ Age Group } & Gender & \multirow{2}{*}{ Total } \\
\cline { 2 - 3 } & Female & Male & \\
\hline$<20$ & 4 & 3 & 7 \\
\hline $21-40$ & 1 & 7 & 8 \\
\hline $41-60$ & 6 & 15 & 21 \\
\hline$>60$ & 1 & 13 & 14 \\
\hline Total & 12 & 38 & 50 \\
\hline
\end{tabular}

Table-2: Clinical symptoms Distribution

\begin{tabular}{|l|l|l|}
\hline & Number & Percentage \% \\
\hline COUGH & 29 & 58 \\
\hline DYSPNEA & 25 & 50 \\
\hline CHEST PAIN & 23 & 46 \\
\hline FEVER & 22 & 44 \\
\hline
\end{tabular}

\section{Observation}

The present study "Role of Multi detector Computed Tomography in evaluation of mediastinal masses" was carried out in the department of Radiodiagnosis, SAMC \& PG Institute, Indore for a period of 18 months. Our study population comprised of 50 patients fulfilling our inclusion and exclusion criteria which were included in the study after taking written informed consent. All the patients referred from all departments with clinical suspicion of mediastinal widening formed our study population. All patients were subjected to MDCT chest and the data collected was meticulously analyzed to characterize patients into one of the various reasons. Following observations were made in our study.

Table-3: Compartmental distribution of mediastinum masses

\begin{tabular}{|l|l|l|}
\hline Compartment & Numbers & Percentage \% \\
\hline SUPERIOR & 10 & 20 \\
\hline ANTERIOR & 25 & 50 \\
\hline MIDDLE & 10 & 20 \\
\hline POSTERIOR & 21 & 42 \\
\hline SUPERIOR AND ANTERIOR & 5 & 10 \\
\hline ANTERIOR AND MIDDLE & 4 & 8 \\
\hline MIDDLE AND POSTERIOR & 3 & 6 \\
\hline MULTIPLE COMPARTMENTS & 4 & 8 \\
\hline
\end{tabular}

Table-4: Anterior Mediastinal Lesions distribution

\begin{tabular}{|l|l|l|}
\hline & No. of Cases & Percentage \% \\
\hline GCT & 1 & 4 \\
\hline Koch's & 3 & 12 \\
\hline Sarcoidosis & 1 & 4 \\
\hline Lymphoma & 9 & 36 \\
\hline Infective MLN (non tubercular) & 3 & 12 \\
\hline Papillary Carcinoma of Thyroid & 1 & 4 \\
\hline Teratoma & 2 & 8 \\
\hline Thymic carcinoma & 1 & 4 \\
\hline Thymoma & 1 & 4 \\
\hline Metastatic Adenopathy & 3 & 12 \\
\hline
\end{tabular}

Table-5: CT enhancement pattern of mediastinal masses

\begin{tabular}{|l|l|l|}
\hline & Number of Cases & Percentage \\
\hline Mild & 14 & 28 \\
\hline Moderate & 26 & 52 \\
\hline Severe & 10 & 20 \\
\hline
\end{tabular}

Table-6: Distribution of the masses based on their nature

\begin{tabular}{|l|l|l|}
\hline & Number of Cases & Percentage \\
\hline Necrosis & 10 & 20 \\
\hline Calcification & 6 & 12 \\
\hline Fluid & 4 & 8 \\
\hline Fat & 3 & 6 \\
\hline
\end{tabular}


Table-7: Calcification

\begin{tabular}{|l|l|l|}
\hline Calcification $(\mathbf{n}=6)$ & Benign & Malignant \\
\hline Thymoma & 1 & - \\
\hline Teratoma & 3 & - \\
\hline GCT & - & 1 \\
\hline Papillary carcinoma thyroid & - & 1 \\
\hline Total & 4 & 2 \\
\hline
\end{tabular}

Table-8: Mass effect on adjoining mediastinal structures

\begin{tabular}{|l|l|l|}
\hline Mass effect & Number of Cases & Percentage \\
\hline Present & 39 & 78 \\
\hline Absent & 11 & 22 \\
\hline
\end{tabular}

\section{DisCUSSION}

The evaluation of mediastinal abnormalities is challenging radio graphically, Cross sectional imaging of the mediastinum by MDCT now demonstrates precise anatomic details and provides excellent delineation of fat, calcium or water attenuation in mediastinal mass, which often suggest a specific diagnosis, so MDCT is the imaging modality of choice for most mediastinal lesions.

In this present study after thorough clinical history and clinical examination, 50 patients were subjected to CT of thorax. Patients were grouped under age, gender, chief presenting complains, location and MDCT patterns. In present study the age groups of the subjects ranged from 10 to 75 years and most were in the age group of $41-60 \mathrm{yrs}$. Male preponderance was observed in our study $76 \%$ being male and $24 \%$ being females, with male to female ratio of 3.1:1 pulasani, et al. [2] observed that out of 50 cases, 30 cases $(60 \%)$ were males, and most common age group to present with mediastinal mass was between 46 and 50 years.

In our study of 50 patients, most common presented with complain of cough $(58 \%)$, dyspnea $(50 \%)$ followed by chest pain $(46 \%)$ and fever $(44 \%)$, these findings were similar to the study conducted by akshatha rao et al.[1], patidar et al.[4], mohmoud EI Bargisy et al.[3], kireet pulsani et al.[2] and drchidananda mishra, et al.[7].

In our study, the majority of masses were in anterior mediastinum constituting 50 , it is similar to the study conducted by arumugam et al. [1] in 2015 where anterior mediastinum constituted $62 \%$, in P.S.S kiran et al. [6] in their study said that anterior mediastinal masses are most common, they constitued $50 \%$ of the masses, In present study most of the mediastinal masses were well defined (66\%), hypodense $(68 \%)$ in density, showed moderate degree of contrast enhancement and heterogenous pattern $(62 \%)$ of contrast enhancement similarity was seen in a study done by Dr Chidananda Mishra et al. [7]who in their study said that most of the masses were hypodense and showed heterogenous enhancement $(40 \%)$.
In our study $20 \%$ of the mediastinal masses showed necrosis, $12 \%$ of the masses showed calcification, in a study done by T. Araki et al. $9 \%$ of the mediastinal masses showed calcification.

Also we saw that $6 \%$ of the mediastinal mass showed fat attenuation and $8 \%$ showed fluid attenuation. $78 \%$ of the mediastinal masses showed mass effect, similarity was noted in the study done by Dr Chidananda Mishra et al. [7] who reported that $4 \%$ of tumours showed fatty attenuation and $12 \%$ showed fluid attenuation and $62 \%$ showed mass effect. Understanding the mediastinal mass distribution of our study, $64 \%$ turned out malignant, $20 \%$ came as benign similarity was noted in a study by murray et al. [10] $85 \%$ were malignant and $15 \%$ were benign mediastinal masses.

Most of the benign lesions in our study were well defined, hypodense, showed mild to moderate degree of enhancement and were homogenous and did not show any infiltration into adjacent structures, also most of the tumours had fat and fluid attenuation and showed calcification, necrosis was a dominant feature of malignant lesions although clinical details had to be considered, study by shahrzad et al. show similarity as they said that visualization of large predominantly solid necrotic, hemorrhagic and enhancing lesion should raise concern for malignancy. Fluid attenuation within the lesion in our study could not help us in deciding the nature of lesion similarity was seen in the study done by murray et al. [10] and Dr. Chidananda Mishra, et al. [7].

\section{CONCLUSION}

This prospective observational study comprised of 50 patients who were clinically suspected to evaluate the cause of mediastinal widening, all the patients were subjected to MDCT of chest to find patterns that fit into one of the cause of mediastinal widening. A final diagnosis was made on the basis of age, gender, clinical profile, dominant compartment and CT characteristics.

\section{The results were summarized as below}

- There were a total of 50 patients in the age group ranging from less than 20 years to more than 60 years, most were in the age group $41-60$ years.

- A male preponderance was observed in our study with $76 \%$ being male and $24 \%$ being female, with male to female ratio of $3.1: 1$.

- The most chief presenting complain was cough 
Manish Bhagat et al; Sch J App Med Sci, Feb, 2021; 9(2): 202-205

(58\%), followed by dyspnea (50\%).

- The majority of masses were in anterior mediastinum constituting 50\%, next common mass were seen in posterior mediastinum (42\%).

- Most common anterior mediastinal mass was Lymphoma (36\%) followed by Kochs (12\%) each, teratomas contributed to $(8 \%)$.

- To conclude the CT Characterstics in present study most of the mediastinal masses were well defined (66\%), hypodense $(68 \%)$ in pre contrast CT, showed moderate degree $(52 \%)$ and heterogenous pattern $(62 \%)$ of contrast enhancement. As per the mediastinal mass distribution of our study $64 \%$ turned out malignant, $20 \%$ came as benign.

- In our study, most of the benign lesions were homogenous and did not show any infiltration into adjacent structures, also most of the tumours had fat $(6 \%)$ and fluid $(8 \%)$ attenuation and showed calcification $(12 \%)$.

- Necrosis (20\%) was a dominant feature of malignant lesions although clinical details had to be considered.

- To draw a conclusion to our study, the majority of masses were in anterior mediastinum (50\%) constituting, lymphoma was most common anterior mediastinal mass $(36 \%)$

\section{REFERENCE}

1. Akshatha Rao Aroor, Rama Prakasha S, ShubhaSeshadri, Teerthanath S., UppoorRaghuraj. Mediastinal Mass. Journal of Clinical and Diagnostic Research. 2014 Feb, 8(2):77-80

2. Pulasani K, Narayanaswamy I, Ramprakash HV. Evaluation of Mediastinal Mass Lesions Using Multi-detector Row Computed Tomography and Correlation with Histopathological Diagnosis. Int J Sci Stud. 2015;3(6):156-163.

3. Mahmoud Abdelhamid El Bargisy, Mahmoud Abdelaziz Dawoud, bdelhady Mohammed Taha, Omar Ahmed Hassanien. Role of Multidetecter CT in Diagnosis of mediastinal masses. The Egyptian Journal of Hospital Medicine April. 2019:75(5): 2763-2768.

4. Patidar N, Patel K, Dutta P, Goyani B. A study of mediastinal mass lesions by various imaging modalities. Int $\mathbf{J}$ Med Sci Public Health. 2016;5:1408-1411

5. Biswajit Dubashi, Sanju Cyriac, Sagar Gnana Tenali Clinicopathological analysis andoutcome of primary mediastinal malignancies. Annals of Thoracic Medicine July-September. 2009: 4(3):140-142

6. Kiran PS, Kalra VB. Computed tomographic evaluation of mediastinal lesions. Journal of Evolution of Medical and Dental Sciences. 2013 Mar 18;2(11):1714-24.

7. Dr. Chidananda Mishra, Dr Satyendra Mohapatra, Dr Savitri Bhagat, Dr Braja Behari Panda. Role of MDCT in Evaluation of Mediastinal Mass. Journal of Medical Science and Clinical Research November. 2019:07(11):302-306

8. Dr. Shruti Santosh Patil and Dr. Richesh S Tathode. Evaluation of mediastinal masses using computed tomography. International Journal of Radiology and Diagnostic Imaging. 2019; 2(2): 3639

9. Mohammad Vaziri1, Abdolreza Pazooki, and Leila Zahedi-Shoolami. Mediastinal Masses: Review of 105 Cases. Acta Medica Iranica. 2009;47(4):298300

10. Rebner M, Gross BH, Robertson JM, Pennes DR, Spizarny DL, Glazer GM. CT evaluation of mediastinal masses. Computerized radiology. 1987 May 1; 11(3):103-10.

11. Karan Thakkar, Saket Mukund Ghaisas and Manmohan Singh. Lymphadenopathy: Differentiation between Tuberculosis and Other non-Tuberculosis Causes like Follicular Lymphoma. Frontiers in Public Health. February. 2016: 4(31):1-4. 